\title{
Body mass index and body image perception in older adults
}

\author{
Ezequiel Pinto*, Dina Carção, Dora Tomé, Jessica Faustino, Liliana Campaniço, Martinha Soares and Nídia Braz \\ Centre for Research and Development in Health, School of Health, University of Algarve, Faro, Portugal
}

\begin{abstract}
Introduction: A significant number of individuals are dissatisfied with their body size and weight, and wish to be thinner. Some of the physical changes associated with aging do not inevitably lead to greater body dissatisfaction but there is evidence suggesting that the importance and concerns attached to appearance and body image may be similar in all ages. This study aimed at analysing body image perceptions, body image satisfaction, and body mass index in older adults.

Methods: We conducted a semi-structured, face-to-face interview in a non-random sample of 72 participants (14 males and 58 females), with no significant cognitive of physical impairments, aged between 65 and 89 years old (Mean=71.6 \pm 6.43 years) who attend classes at a community education institution in the municipality of Faro, in the Portuguese region of the Algarve. Participants also completed the Body Shape Questionnaire and consented to anthropometric assessment using standard methods.

Results: Most of the participants (75\%) declared to be satisfied or very satisfied with their current body, but $40 \%$ underestimated and $31 \%$ overestimated their body size. Men showed an higher prevalence of selecting an ideal contour drawing heavier than perceived body image $\left(\mathrm{X}^{2}=1.34 ; \mathrm{p}=0.037\right)$ and women select more frequently an ideal contour drawing thinner than perceived body image $\left(\mathrm{X}^{2}=1.41 ; \mathrm{p}=0.027\right)$. BMI was negatively correlated with body image satisfaction $\left(\mathrm{r}_{\mathrm{S}}\right.$ and positively correlated with selecting a contour drawing thinner than current perceived body image $\left(\mathrm{r}_{\text {Spearman }}=0.53, \mathrm{p}<0.001\right)$. $=-0.37, \mathrm{p}=0.001)$
\end{abstract}

Conclusions: Older individuals seem to have a high body satisfaction, despite misperceiving body image, and BMI appears to be a risk factor for body dissatisfaction in older adults. Health education and advice for self-care should take into account body image perception and body dissatisfaction issues.

\section{Introduction}

Appearance has become a very important construct in contemporary Western societies and there is a great deal of evidence suggesting that appearance self-perception is experienced negatively by a significant number of individuals, who are dissatisfied with their body, particularly with their body size and weight, and wish to be thinner [1-3]. There is also increasing evidence that appearance esteem and satisfaction represent probably the major contributors to overall levels of global self-esteem [4]; that is, they are very important components of how individuals feel about themselves.

Body size estimation distortion plays a role in the incidence of eating disorders, and several literature reviews identify body size overestimation as a risk factor for the development of eating disorders, and a predictor of treatment failure, lack of clinical progress, and poor clinical outcomes after diagnosis.

The inability to match up to the unrealistic ideal appearance results in body dissatisfaction, which may lead to behaviours related to disordered eating. Nevertheless, appearance self-management is not always negatively motivated, and people also engage in proactive, purposeful self-regulatory behaviours to control evaluative body image and other self-reinforcing consequences [5].

The single most consistent risk factor for body dissatisfaction is BMI, and much of the research on body image is based on BMI assessment in adolescent and young adults [6], but a growing body of evidence suggests that although some of the physical changes associated with aging (e.g., increases in body weight, skin wrinkling, reduction in body tone and muscularity) may take people farther away from a socially idealized slender, wrinkle-free, and toned body, but do not inevitably lead to greater body dissatisfaction [7]. On the other hand, there is also evidence suggests that the importance and concerns attached to appearance and body image may be similar in all ages [5]. Thus, our study aimed at analysing body image perceptions, body image satisfaction, and body mass index (BMI) in older adults.

\section{Methods}

We conducted a semi-structured, face-to-face interview in a nonrandom sample of 72 participants (14 males and 58 females), with no significant cognitive of physical impairments, aged between 65 and 89 years old (Mean $=71.6 \pm 6.43$ years) who attend classes at a community education institution in the municipality of Faro, in the Portuguese region of the Algarve.

Interviewers were trained dietitians, who assessed sociodemographic characteristics, body image satisfaction (a single question, answered in a numbered scale ranging from 1-Unsatisfied to 4-Very satisfied), and body image questions, supported by the Body Shape Questionnaire, a validated contour drawing scale in which the subjects selected a picture they believed represented their current body image and their ideal body image $[8,9]$. This contour drawing scale comprises a set of nine contour drawings for each gender, showing escalating measures from leaner to wider body. Each drawing depicts a specific BMI value, not shown in the figures, which ranges between 17.5 and $37.5 \mathrm{~kg} / \mathrm{m}^{2}$. Interviewers also

Correspondence to: Ezequiel Pinto, Universidade do Algarve, Escola Superior de Saúde, Av. Dr. Adelino da Palma Carlos, 8000-510 Faro, Portugal, Tel: +351 289 800 100; E-mail: epinto@ualg.pt

Key words: Body image, body shape questionnaire, older adults

Received: October 10, 2017; Accepted: November 14, 2017; Published: November 17, 2017 
assessed height and weight using standard anthropometry procedures. For the purpose of this study and to analyse the data, we defined underestimating body size as selecting a contour drawing with a BMI at least $2.5 \mathrm{~kg} / \mathrm{m}^{2}$ below current BMI and overestimating as selecting a contour drawing with a BMI at least $2.5 \mathrm{~kg} / \mathrm{m}^{2}$ above current BMI.

All stages of this study obeyed the ethical rules for health sciences research as stated in the sixth revision of the Declaration of Helsinki, including an informed consent form which was signed by every participant during the briefing and recruitment.

Data were analysed with IBM-SPSS software version 24.0 (SPSS Inc., Chicago, IL, USA). Participants' description and characterization were presented as mean values accompanied by standard deviations, and prevalence calculated as the percent of the total number of valid observations in each calculation.

The Kolmogorov-Smirnov test was used to assess adherence to the Normal distribution and Student's t-test or Mann-Whitney's U were computed for comparisons between two groups. Correlations were analysed with Spearman's correlation coefficient. The chi-square test $\left(\mathrm{X}^{2}\right)$ was used for group comparisons of qualitative variables.

Statistical significance in all procedures was determined by twotailed analysis and set at 0.05 .

\section{Results}

The final sample was composed by 72 patients, $19 \%$ males $(n=14)$ and $81 \%$ females $(n=58)$, with ages ranging between 65 and 89 years old $(\mathrm{M}=71.6 ; \mathrm{SD}=6.43)$. Men had a higher mean age $(\mathrm{M}=72.2, \mathrm{SD}=6.23)$ than women $(\mathrm{M}=71.4, \mathrm{SD}=6.52)$ but differences were not statistically significant $(\mathrm{U}=358.5 ; \mathrm{p}=0.497)$. Regarding educational level, $29 \%$ $(n=21)$ of patients completed only up to 4 years of schooling, $35 \%$ $(n=25)$ had up to 12 years of schooling, and $36 \%(n=26)$ have a higher education degree. Mean BMI for the participants was $26.2 \mathrm{~kg} / \mathrm{m}^{2}$ $(\mathrm{SD}=3.16)$. We did not find gender differences in both educational level $\left(\mathrm{X}^{2}=1.79 ; \mathrm{p}=0.407\right)$ or BMI $(\mathrm{t}=-0.72, \mathrm{p}=0.472)$.

Most of the participants, again without significant gender differences $\left(\mathrm{X}^{2}=1.31 ; \mathrm{p}=0.728\right)$, declared to be satisfied $(72 \%)$ or very satisfied with their current body (3\%). Table 1 shows the distribution of BMI categories and the distribution of body image satisfaction.

Despite the overall satisfaction with body image, we found that $40 \%$ of participants underestimated and $31 \%$ of participants overestimated their body size, when compared with the BMI assessed by the researchers (Table 1).

Regarding ideal body image, when asked to select a contour drawing which corresponds to a body that participants consider to be their ideal body, $64 \%$ select a contour drawing that is thinner than the contour drawing selected as representing current body image, $4 \%$ select a contour drawing that is heavier than perceived body image, and $32 \%$ select the same contour drawing as the one selected as current body image. We found gender differences in ideal body image. While men have a higher prevalence of selecting an ideal contour drawing heavier than perceived body image $\left(\mathrm{X}^{2}=1.34 ; \mathrm{p}=0.037\right)$, women select more frequently an ideal contour drawing thinner than perceived body image $\left(\mathrm{X}^{2}=1.41 ; \mathrm{p}=0.027\right)$.

BMI assessed by the researchers was found to be negatively correlated with body image satisfaction, indicating that participants with higher BMI were less satisfied with their body image $\left(\mathrm{r}_{\text {Spearman }}=-0.37, \mathrm{p}=0.001\right)$. High BMI was also correlated with selecting a contour drawing thinner than current perceived body image $\left(\mathrm{r}_{\text {Spearman }}=0.53, \mathrm{p}<0.001\right)$.
Table 1. Body image satisfaction, BMI categories and body image perception, by gender.

\begin{tabular}{|c|c|c|c|c|c|c|}
\hline \multirow{2}{*}{ Variables } & \multicolumn{2}{|c|}{$\operatorname{Men}(N=14)$} & \multicolumn{2}{|c|}{ Women $(\mathrm{N}=58)$} & \multicolumn{2}{|c|}{ Total $(\mathrm{N}=72)$} \\
\hline & $\mathrm{N}$ & $\%$ & $\mathrm{~N}$ & $\%$ & $\mathrm{~N}$ & $\%$ \\
\hline \multicolumn{7}{|l|}{ Body image satisfaction } \\
\hline Unsatisfied & 1 & $7 \%$ & 2 & $3 \%$ & 3 & $4 \%$ \\
\hline Slightly satisfied & 2 & $14 \%$ & 13 & $23 \%$ & 15 & $21 \%$ \\
\hline Satisfied & 11 & $79 \%$ & 41 & $71 \%$ & 52 & $72 \%$ \\
\hline Very Satisfied & 0 & $0 \%$ & 2 & $3 \%$ & 2 & $3 \%$ \\
\hline \multicolumn{7}{|l|}{ BMI categories* } \\
\hline Normal weight & 4 & $29 \%$ & 19 & $33 \%$ & 23 & $33 \%$ \\
\hline Overweight & 9 & $64 \%$ & 31 & $53 \%$ & 40 & $56 \%$ \\
\hline Obese & 1 & $7 \%$ & 8 & $14 \%$ & 9 & $11 \%$ \\
\hline \multicolumn{7}{|l|}{ Body image perception } \\
\hline Underestimated & 7 & $50 \%$ & 22 & $38 \%$ & 29 & $40 \%$ \\
\hline Adequate & 1 & $7 \%$ & 20 & $35 \%$ & 21 & $29 \%$ \\
\hline Overestimated & 6 & $43 \%$ & 16 & $28 \%$ & 22 & $31 \%$ \\
\hline \multicolumn{7}{|l|}{ Ideal body image (BI) perception } \\
\hline Ideal BI heavier than current BI & 1 & $7 \%$ & 2 & $3 \%$ & 3 & $4 \%$ \\
\hline Similar current and ideal BI & 7 & $50 \%$ & 16 & $28 \%$ & 23 & $32 \%$ \\
\hline Ideal BI thinner than current BI & 6 & $43 \%$ & 40 & $69 \%$ & 46 & $64 \%$ \\
\hline \multicolumn{7}{|c|}{$\begin{array}{l}\text { * Interpreted according to World Health Organization. Physical status: the use and } \\
\text { interpretation of anthropometry. Report of a WHO Expert Committee. Geneva, } \\
\text { Switzerland; WHO, } 1995\end{array}$} \\
\hline
\end{tabular}

\section{Discussion and conclusions}

Our data show that older individuals seem to have a high body satisfaction, despite misperceiving body image. This is contrary to the literature, which suggests a high prevalence of body dissatisfaction, regardless of BMI [7]. The literature suggests that the high prevalence of body dissatisfaction can be the result of worsened physical function and health problems related with age [3]. As in our sample participants did not have any cognitive impairment or significative physical limitation, our data can differ from the literature on this account.

The gender differences found in our data are in accordance with the literature which states that women, independently of age and more than men, desire to be thinner [2].

The associations we found between BMI and body image perception and body dissatisfaction support the literature that identifies BMI as a risk factor for body dissatisfaction in all ages $[3,5]$.

Our results show that health education and advice for self-care should take into account body image perception and body dissatisfaction issues. For example, nutrition education and medical nutrition therapy adherence may benefit from a tailored approach that considers body image perception. Additional research is needed to characterize body shape ideals, which are yet to be analysed across age groups.

This study presents some limitations, related to sample size and sampling method, which may have resulted in a particular cluster of participants that do not represent older adults in other settings. The characteristics that make them attend voluntary classes in a community education institution can distinguish them from other older adults in the same population. Thus, additional research, with a larger and heterogeneous sample is recommended. Nevertheless, our results allowed us to analyse body image perception and BMI in a group that is seldom studied in regard to this topic [10].

\section{Ethical statement}

We declare that this study followed all necessary ethical procedures and regulations. 


\section{Conflict of interest disclosure statement}

The authors did not receive any funding for this research and confirm that the content of this article has no conflict of interest.

\section{References}

1. Clarke LH, Korotchenko A (2011) Aging and the Body: A Review. Canadian journal on aging 30: 495-510.

2. Roy M, Payette H (2012) The body image construct among Western seniors: A systematic review of the literature. Arch Gerontol Geriatr 55: 505-521 [Crossref]

3. Tiggemann $\mathrm{M}$ (2015) Considerations of positive body image across various social identities and special populations. Body Image 14: 168-176.

4. Wilson R, Latner J, Hayashi K (2013) More than just body weight: The role of body image in psychological and physical functioning. Body Image 10: 644-7. [Crossref]
5. Becker CB, Verzijl CL, Kilpela LS, Wilfred SA, Stewart T (2017) Body image in adult women: Associations with health behaviors, quality of life, and functional impairment. $J$ Health Psychol [Crossref]

6. Calzo JP, Sonneville KR, Haines J, Blood EA, Field AE, et al. (2012). The Development of Associations Among BMI, Body Dissatisfaction, and Weight and Shape Concern in Adolescent Boys and Girls. The Journal of adolescent health 51: 517-523. [Crossref]

7. Raso V, Garber, CE, Mancini RB, Matsudo SMM (2016) Body image in a representative sample of overweight, obese and normal weight active older women living in the community: associations with body composition, physical fitness and function. MedicalExpress 3.

8. C Rosen J, Jones A, Ramirez E, Goldstein S (1996) Body Shape Questionnaire: Studies of validity and reliability 20: 315-319. [Crossref]

9. Conti MA, Cordás TA, Latorre (2009) A study of the validity and reliability of the Brazilian version of the Body Shape Questionnaire (BSQ) among adolescents. Revista Brasileira de Saúde Materno Infantil 9: 331-338.

10. Kakeshita IS, Almeida SS (2008) The relationship between body mass index and body image in Brazilian adults. Psychology \& Neuroscience 1: 103-107.

Copyright: $@ 2017$ Pinto E. This is an open-access article distributed under the terms of the Creative Commons Attribution License, which permits unrestricted use, distribution, and reproduction in any medium, provided the original author and source are credited. 